\title{
BIBLIOMETRIC ANALYSIS OF STUDIES IN MEDICINAL AND AROMATIC PLANTS FOR RURAL DEVELOPMENT
}

\author{
Muhittin Kulak \\ Aralik University, Turkey \\ muhyttynx@gmail.com
}

\begin{abstract}
Medicinal and aromatic plants (MAPs) are of interest for human uses from the prehistoric times to the present day. Importance and demand for medicinal and aromatic plants are always continuous. The plant-based drugs, health products, pharmaceuticals, food additives, and cosmetics may contribute to economics for the people living in rural areas as an alternative economic value chain for developing countries. The strategy and priority for selection of some elite plants for their conservation, cultivation, processing, and standardization may promote a new way of livelihood in rural areas. However, quantitative data are lacking on the profile of published researches regarding rural development and MAPs across the world. The object of the study was to examine the profile of original and review articles under the topic of rural development using bibliometric analysis. The VOSviewer tool was used to visualize the results. The documents including "rural development in "Article title, Abstract, Keywords", but limited to containing the topic "medicinal and aromatic plants" were extracted from the Scopus database. Briefly, the research was done using rural development in "Article title, Abstract, Keywords" and then 70,745 documents were retrieved. The second step was limitation of the results to "medicinal and aromatic plants". In this context, 113 documents relevant and available peer-reviewed publications were analysed. According to the systematic analysis, 4169 terms, 346 authors, 384 keywords and 56 countries were determined. The annual trends of publications in the field of the research, considering the number of documents, number of authors, levels of collaborations among authors and countries, yearly publications and core publishing journals were analysed. Along with the results, medicinal plants, Himalaya, conservation, Ethnobotany, Nepal, traditional knowledge, rural development, sustainable development, domestication, Ethnomedicine, livelihood, non-timber forest products, value chain and marketing are of the most pronounced keywords and the discussion was made on those keywords. Of these studies, India, the United States, Italy, Nepal and South Africa were the predominant five countries in dissemination of the documents. Finally, the study was concluded with future outlooks and recommendations.
\end{abstract}

Keywords: bibliometric analysis, medicinal and aromatic plants, rural development.

\section{Introduction}

Countries must use their resources efficiently in order to ensure the well-being and happiness of the population. Regardless of the economic system, in which they are implemented, the fundamental questions that country economies are in search of answers are universal. Geray (1991) [1] and Tolunay and Akyol (2006) [2] reported the basic questions regarding economic structures of the countries, highlighting the appropriate answers for the questions. Those questions were described as follows: i) Which goods should be produced? ii) How much of the goods should be produced? iii) Which technologies should be used for production? iv) What should be apportionment of the goods?

The EU framework for rural development programmes (2014-2020) has focused on the needs of the territories of the member states and regions, addressing some common EU priorities. These can be sorted as i) fostering knowledge transfer and innovation, ii) enhancement of the viability and competitiveness, iii) promotion of food chain organisation, animal welfare and risk management, iv) conservation of ecosystems, v) encouragement uses of resources efficiently and environmentally sustainable economy, vi) promotion of social inclusion, poverty reduction and sub sequential economic development in rural areas (Rural development 2014-2020).

In order to combat poverty and inequality, development concept of rural areas has been addressed with different approaches in various developing countries [3]. The question "Why should we care about rural regions today?" has been well and deeply discussed and the answers have been proposed in many approaches by [4]. The reason why population in rural areas have been addressed is to start with urbanization for seeking economic and social opportunities for rural people. Moreover, no more people have been needed for agricultural production after introduction of new and latest agrotechnologies to the rural areas. Consequently, the decline in employment and population in rural areas has been considered as consequences of natural processes of national development. It is worthy to underline that majority of poor people live in rural areas. This situation has been recognized by the World Bank considering that rural development is significant for improving the quality of life in most 
of the developing countries in Africa, Asia and Latin America and conducting programs regarding technology transfer, access to services and economic conditions in rural areas. It is furthermore emphasized that the economies of most developing countries have been based on uses of natural resources involving both renewable and non-renewable ones. Along with the economical income, rural people are the important key-players concerned with environmental protection [4].

Today, there is an increasing demand and interest in the plant based products and cosmetics. With increasing in human population, this interest caused challenging tasks of meeting the needs of people because collection of wild plants has not still adopted a system for sustainable agricultural production and harvesting practices of these plants. Kala (2010)[5] underlined that the studies have been conducted with respect to exploring of domestication possibilities of wild-collected medicinal plants through rural and modern technologies. It was moreover emphasized that the issues regarding bioprospecting, identification of sustainable harvesting practices, safety and standardization of herbal drugs, strengthening legislation and policy on medicinal plants, developing market infrastructure, supply chain management are also of interest for the programmes or studies [5].

In the report disseminated by the Middle Anatolia Development Agency, Turkey (ORAN) in 2015 , it has been highlighted that as of the natural resources, medical and aromatic plants play a social, cultural and ecologically valuable role in local communities around the world [6]. The production of medicinal and aromatic plants is an alternative method of production, particularly in rural areas, which contributes to the reduction of unemployment and the increase in agricultural income due to intensive labour demand [7].

Along with the present study, the following research questions (RQ) were examined:

$R Q 1$ : What is the spatial distribution of the rural development with medicinal aromatic plants related studies?

RQ2: Where have the studies been focused? Which keywords-core content of the studies-have been mostly proposed?

$R Q 3: \quad$ What can be done for rural development on the basis of professional support?

\section{Material and methods}

\section{Why bibliometric analysis?}

As a methodology, the VOSviewer tool was used to visualize the results. The documents including "rural development in "Article title, Abstract, Keywords", but limited to containing the topic "medicinal and aromatic plants" were extracted from the Scopus database. Briefly, the research was done using rural development in "Article title, Abstract, Keywords" and then 70,745 documents were retrieved. The second step was limitation of the results to "medicinal and aromatic plants". In this context, 113 documents relevant and available peer-reviewed publications were analysed.

\section{Results and discussion}

What do the terms extracted from the documents tell us?

For analysis of the terms, minimum number of occurrences of a term was considered to be 5. Of the 4169 terms, 202 meet the threshold. For each of the 202 terms, a relevance score was calculated. Based on the estimated score, the most relevant term was selected. The default choice was to select $60 \%$ of the most relevant terms. The number of the terms to be selected was 121 . According to the analysis results, three clusters were identified (Figure 1).

Red cluster was found to be about livelihood security challenges including sustainable development, agriculture, climatic changes, biodiversity and yields. For sure, environmental challenges are essential issues for all people, but the reality of livelihood of rural people should not be ignored. Rural people are more vulnerable in response to any sharp or sudden climatic problems. As stated by De Haen (2007) [8], these people are more dependent on ecosystem services than any other segment of human beings. This is one of the major issues for almost one billion poor and more than 800 million people in rural areas. These people sustain their lives depending directly or indirectly on agriculture. Their sustenance is provided from using lands and water as farmers and fisher folks. Using forests and biodiversity for food, fodder, fuels, shelters, and non-wood forestry products for various purposes are of the ways of sustenance. The author highlighted that the rural ecosystems with rural 
people inside have been shaped and conserved over thousands of years. Since the ecosystems are dynamic, vulnerable to any changes and with increasing population pressure and lacking alternatives, the land and livestock have been used beyond their carrying capacity.

Green cluster was considered to be a traditional medicinal system involving the terms such as used parts of plants, drugs and preparation. We know that for this alternative healing system, the wild collection for the healing system is done. With the increasing population pressure and its consequences of excessive and unconscious harvesting, there has been decline in the naturally spread plants. These problems entail an alternative wild to the agricultural production system. We should note that implementation of the system is more complex than predicted. Many challenges such as appropriate plant species for agricultural production, plant species adaptive to the climatic conditions of the regions and the market value of the plant species are some of the issues.

Blue cluster is consequences of commercialization, market, market value and trade. Along with the clusters, we can deduce that the clusters are intertwined and all terms must be discussed in relation to each other. Finally, we can highlight that coherent strategies, appropriated infrastructures, coordinated programs, strong management of governmental structures and diversification in agricultural activities are the desired steps in rural areas and rural development [9-10].

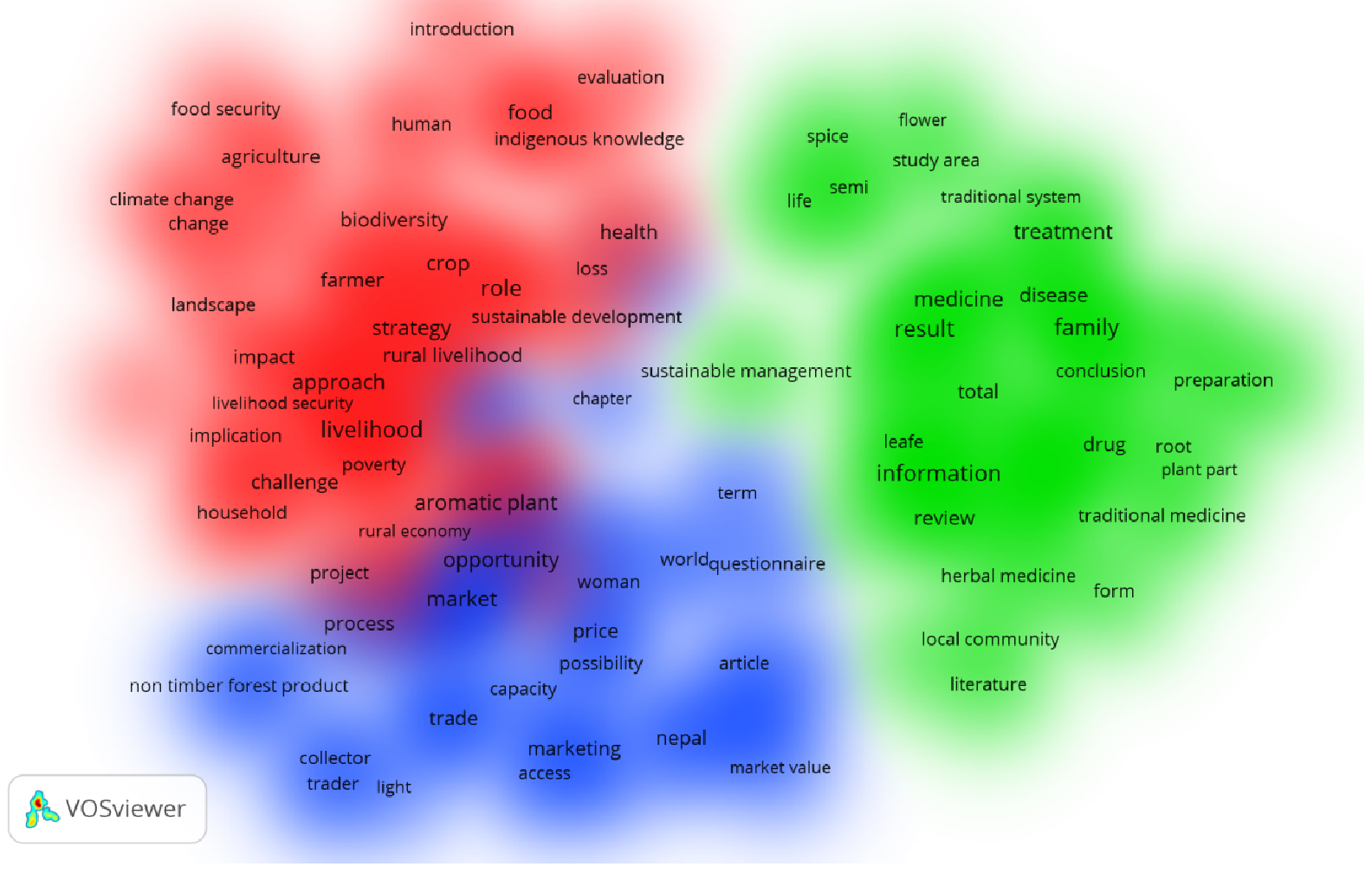

Fig. 1. Occurrences of terms

\section{Geographical Distribution}

To determine the geographical distribution of the documents, a minimum number of documents of a country was considered as one document. Citations per document were ignored. Initially 61 countries were listed, but two undefined countries were excluded. Then, some of the 56 items in the networks were found not to be connected with each other. Hence, the largest set of connected items consisted of 38 items. The remaining set of items was shown instead of all items. For country analysis, 7 clusters with 38 items were identified (Figure 2). Of these studies, India, the United States, Italy, Nepal and South Africa were the predominant five countries in dissemination of the documents (Figure 3). 


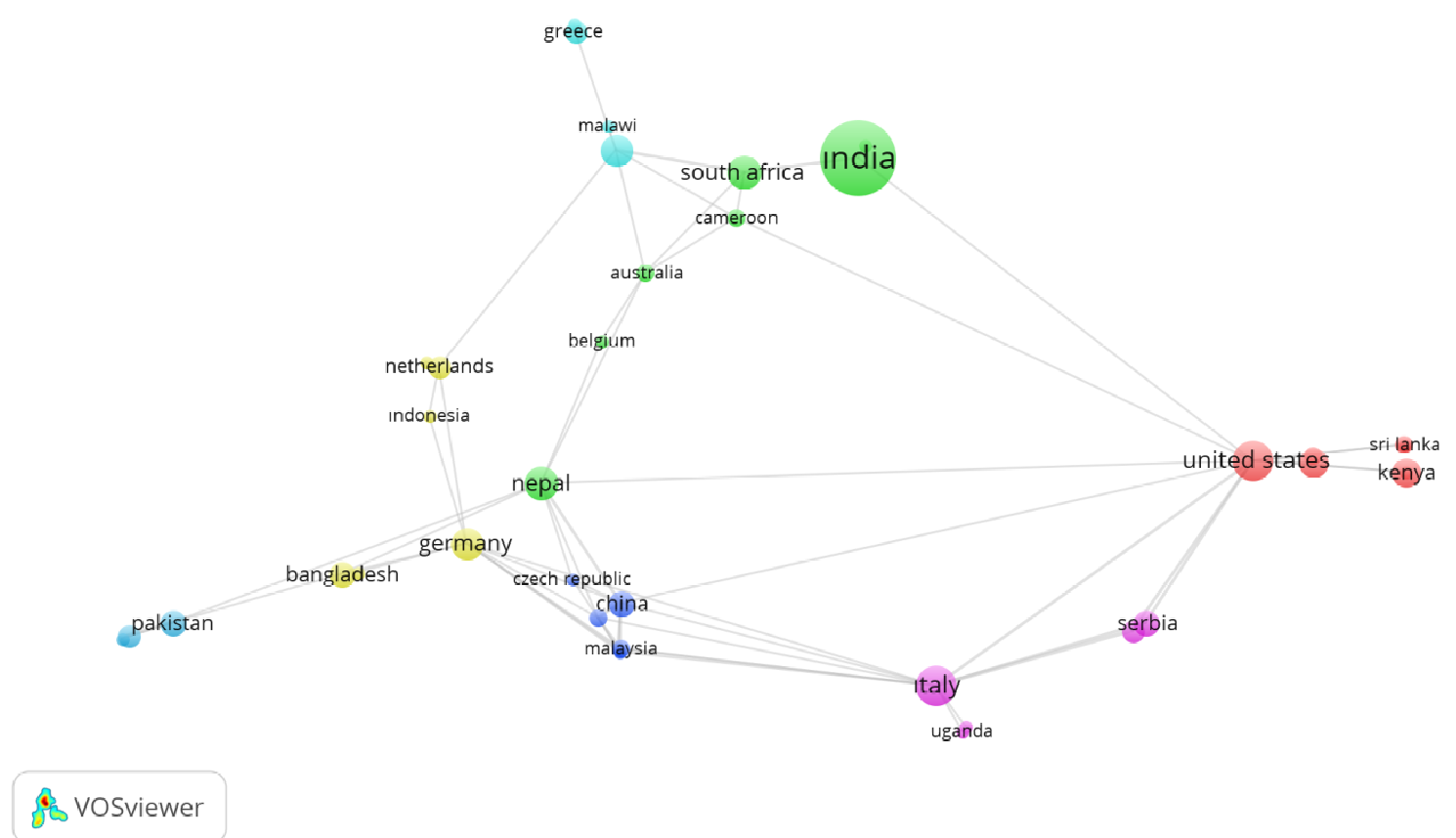

Fig. 2. Co-authorship network of countries

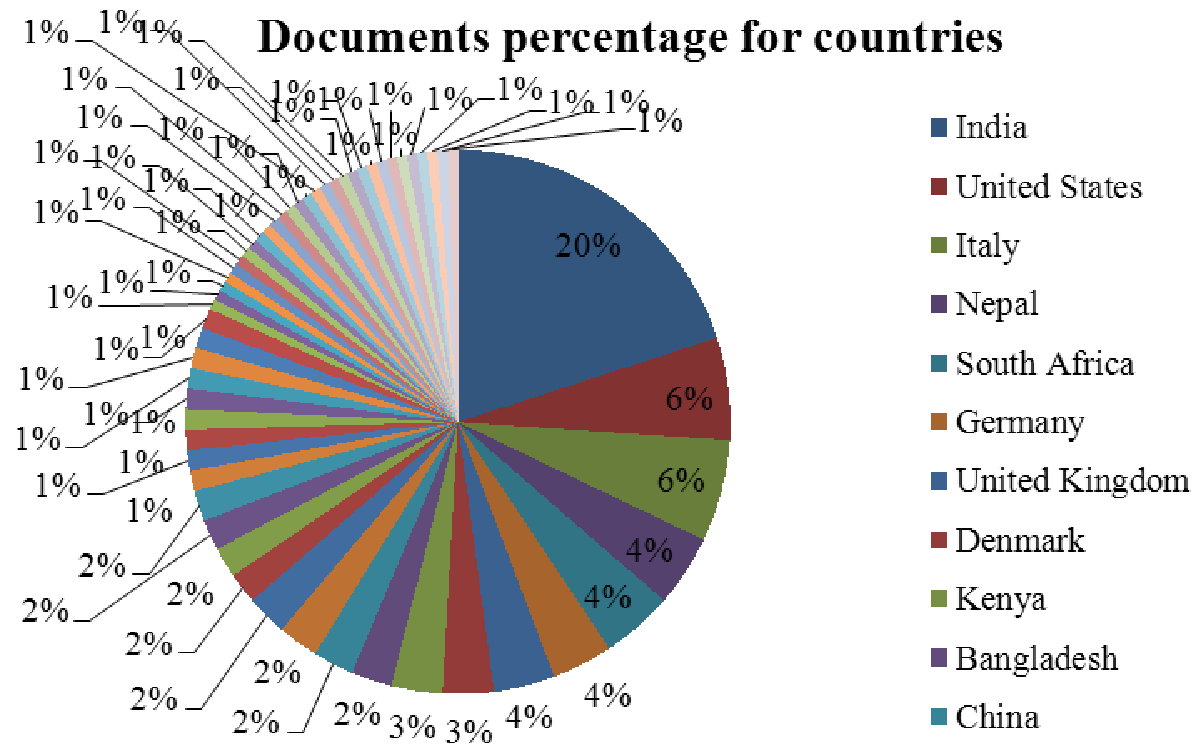

Fig. 3. Countries publishing studies regarding medicinal and aromatic plants and rural development

What do the terms proposed by the authors in the documents analysed tell us? Can they be pioneers for the future studies?

The simple keyword extraction provides raw information about the research topics, but they are assigned to documents to represent the core content of their papers. In this regard, keyword analysis can be used to determine the progress in the research frontiers associated with knowledge [11], proposing the gap of keyword analysis in rural development with medicinal and aromatic plants studies. Herewith the core results, this section should be considered as the most important contribution of the manuscript [12].Co-occurrence and the author keywords might be considered as one of the factors to provide information on rural development coupled with plants and their products. In this context, one keyword was considered as the minimum number of occurrences of a keyword. 384 keywords were considered for evaluation. For each of the 384 keywords, the total strength of the cooccurrence links with the other keywords was calculated (Figure 4). The keywords with the greatest 
total link strength were selected. All keywords were selected. Some of the 384 items in the network were not connected to each other. The largest set of connected items consisted of 259 items. Hence, this set of items was shown instead of all items. Accordingly, 259 items were included in 23 clusters.

Along with the results, medicinal plants, Himalaya, conservation, Ethnobotany, Nepal, traditional knowledge, rural development, sustainable development, domestication, Ethnomedicine, livelihood, non-timber forest products, value chain and marketing are the most pronounced keywords.

The most of the studies have been disseminated from India because of the fact that India is clearly known to be the richest source of medicinal plants. Surely, the richness is not a unique reason. The World Health Organization estimates that over $80 \%$ of the world's population relies and meets their health care needs on the basis of the traditional medicinal system. Mazid et al. (2012)[13] states the contribution of collection and processing of medicinal plants and their products each year to the national economy of India, providing both full and part time employments. A large number of the employed were women. Women economic empowerment would be ensured through economic activity to the rural development. Consequently, women would have possibilities of higher income that would subsequently give them an economic role not only within the household, but also outside [5].

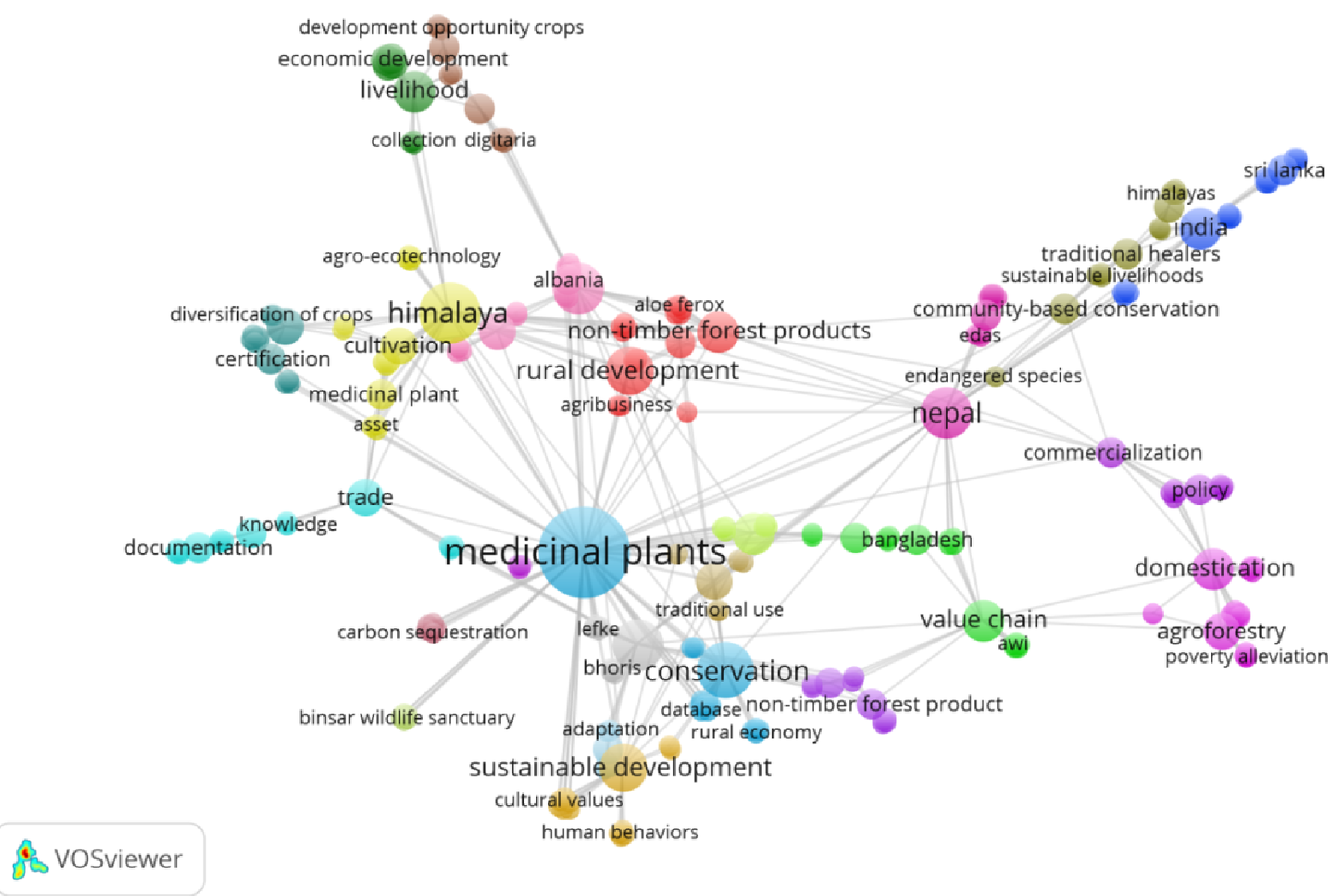

Fig. 4. Visual representation of keywords based on co-occurrence

Core journals

The studies were mostly concentrated in Acta Horticulturae (9), Journal of Ethno-pharmacology (9), Journal of Ethnobotany and Ethnomedicine (4), Biodiversity and Conservation (3), Journal of Medicinal Plants Research (3) and Mountain Research and Development (3).

Future outlook

Medicinal plants are the major and important group of crops, which possess significant values in the socio-cultural, spiritual and medicinal use in rural and tribal lives of the developing countries [14]. It is estimated that 50,000 to 80,000 flowering plants are consumed for medicinal purposes [15]. According to the World Health Organization reports, about $80 \%$ of the world populations still rely on medicinal herbs for their medicinal therapeutic effects[16-17].It is worthy to note that the uses of these plants are not only limited to medicinal purposes such as plant-based drugs, health products and pharmaceuticals, but they are also used in food additives and cosmetics for their aromatic value[1822].In this section, some recommendations have been listed in order to get an alternative economic 
income with optimal plant yield coupled with the desired content of metabolites for consumers. That may be possible with the professional help from authorities.

1. Coherent strategies, appropriated infrastructures, coordinated programs, strong management of governmental structures and diversification in agricultural activities are desired steps in rural areas and rural development [9-10].

2. Plants that would be sources for rural development might be of great interest of the economic value, medicinal and aromatic value. Then, each determined plant must be compatible with ecological conditions of the region.

3. It is worthy to note that high yield of plants does not mean high quality for the consumer. The efficacy of the plants is characterized by their content and composition of the metabolites. The metabolite contents are diurnal, ontogenetic and morphogenetic dependent. Hence, the reactions against any environmental stimuli by the plant itself are metabolite-dependent. In this context, appropriate harvesting times and plant organs should be monitored for the potent metabolites.

4. Another issue is fertilization for high yield or coping with unfavourable conditions. Each plant species has its unique characters and hence the response to fertilization would be different. Fertilization type, fertilization time, fertilization frequency, fertilization application form and fertilization concentration are essential matters for plants. For this stage, professional support is a necessity.

5. After plausible yield of the plants, the next stage is to turn raw materials of the plants into marketable goods for monetary value. In this context, the role of stakeholders ranging local traders, exporters, traditional and professional healing bodies are other basic issues [24].

6. Extensive and comprehensive collaboration between private, non-governmental organizations and governmental structures is an obligation for rural development.

Highlights of the study

Up to best knowledge, this is the first bibliometric analysis of rural development with medicinal and aromatic plants. The network of the keywords and frequently used terms related to the content of the study was presented. Along with the study, we can conclude that the study and attempts for rural development through plant and plant products are not detailed yet.

\section{Limitations of the study}

Although this is the first study-up to our best survey-to present the most comprehensive and specific view of available research on rural development coupled with medicinal and aromatic plants from the largest existing database, we have several limitations in this study. (1) We only extracted data from SCOPUS and so documents in non-indexed plant journals have not been considered. (2) The search was restricted to the words "rural development" in the title and abstracts and then the obtained results were limited to "medicinal and aromatic plants". (3) Hence, some publications might not contain rural development, medicinal and aromatic plants concerned terms in the publication title and abstracts, so it is possible that not all publications related to the present study were identified.

\section{Conclusions}

The main conclusions of the study have been listed as follows:

1. The results of the study were visualized through the VOSviewer tool. Three clusters were identified for terms extracted from the relevant studies, but the clusters should not be discussed separately. All of them are intertwined and holistic and integrative views are needed for understanding the processes of livelihood-environmental conditions and commercialization for rural development.

2. India with its rich biodiversity is one of the predominant countries in documentation of the rural development with medicinal plants related studies.

3. For the cluster analysis of keywords, 259 keywords were included in 23 clusters. Ethnobotany, rural and sustainable development, domestication, value chain and marketing are some of the pronounced keywords.

4. Finally, it can be concluded that an integrative collaboration of private, non-governmental and governmental structures is a prerequisite for rural development. 


\section{References}

[1] Geray U. Ekonomi, İ.Ü. Orman Fakültesi Yayınları, İ.Ü. Yayın No: 3633, Or. Fak. Yayın No:408, 1991, İstanbul, Türkiye. (In Turkish)

[2] Tolunay A., Akyol A. Kalkinma ve kırsal kalkınma: Temel kavramlar ve tanımlar. Süleyman Demirel Üniversitesi Orman Fakültesi Dergisi, vol. 2, 2006, pp. 116-127.

[3] Obadire O. S., Mudau M. J., Sarfo-Mensah P., Zuwarimwe, J.Active role of stakeholders in the implementation of comprehensive rural development programme in South Africa. International Journal of Humanities and Social Science, vol. 3(13), 2013, pp. 273-280.

[4] Green G. P. (Ed.). Handbook of rural development. Edward Elgar Publishing, 2013. 384 p.

[5] Kala C. P. Medicinal Plants and Sustainable Development. First edition. New York, USA: Nove Sciece Publishers, 2011. 280 p.

[6] Marshall E. Health and Wealth from Medicinal Aromatic Plants. FAO Diversification Booklet 17. Rural Infrastructure and Agro-Industries Division Food and Agriculture Organization of the United Nations, Rome 2011. ISSN 1810-0775.

[7] Faydaoğlu E. Sürücüoğlu M.S. Bitkilerin geleneksel tedavideki yeri ve önemi. "X. Ulusal ekoloji ve çevre kongresi”, 04-07 Ekim 2011, Çanakkale, Türkiye

[8] De Haen H. Climate change and rural development.entwicklung \& ländlicher raum, vol. 5, 2007, pp. 4-8.

[9] Namdar R., Sadighi H. Investigation of major challenges of rural development in Iran utilizing Delphi technique. Journal of Agricultural Science and Technology, vol. 15(3), 2013, pp. 445-455.

[10] Noorhosseini S. A., Fallahi E., Damalas C. A., Allahyari, M. S.Factors affecting the demand for medicinal plants: Implications for rural development in Rasht, Iran. Land Use Policy, vol. 68, 2017, pp. 316-325.

[11] He Q. Knowledge discovery through co-word analysis. Library Trends, vol. 48, 1999, pp. 133159.

[12] Hu Z, Guo F, Hou H. Mapping research spotlights for different regions in China. Scientometrics, vol. 110(2), 2017, pp. 779-790.

[13] Mazid M., Khan T. A., Mohammad F. Medicinal plants of rural India: a review of use by Indian folks. Indo Global Journal of Pharmaceutical Sciences, vol. 2(3), 2012, pp. 286-304.

[14] Hendawy S.F., Ezz El-Din A.A., Aziz E.E., Omer E.A. Productivity and oil quality of Thymus vulgaris L. under organic fertilization conditions. Ozean J. Appl. Sci., vol. 3, 2010, pp. 203-216.

[15] Naguib N.Y.M. Organic Vs Chemical Fertilization of Medicinal Plants: A Concise Review of Researches. Advances in Environmental Biology, vol. 5, 2011, pp. 394-400.

[16] Sharafzadeh S., Zare M. Effect of drought stress on qualitative and quantitative characteristics of some medicinal plants from Lamiaceae family: a review. Advances in Environmental Biology,2011, pp. 2058-2063.

[17] Aghaei K., Komatsu S. Crop and medicinal plants proteomics in response to salt stress. Frontiers in Plant Science, 2013, pp. 4, 1-9.

[18] Iqbal M. Invited commentary: From medicine to phytomedicine. Annals of Phytomedicine, vol. 2(1), 2013, pp. 1-2.

[19] Pushpangadan P. Invited commentary: Ethnopharmacology and phytomedicine. Annals of Phytomedicine, vol. 2(2), 2013, pp.1-3.

[20] Yaldiz G., Kulak M. Assessment on adaptation of some selected medicinal and aromatic plants to the northern parts of Turkey: Agricultural and chemical property based evaluation. J. Med. Aromat. Plant Res., vol. 2(3), 2014, 50-56.

[21] Skotti E., Anastasaki E., Kanellou G., Polissiou M., Tarantilis P.A. Total phenolic content, antioxidant activity and toxicity of aqueous extracts from selected Greek medicinal and aromatic plants. Ind. Crops Prod., vol. 53, 2014, pp. 46-54.

[22] Udupa N. Invited commentary: Status on herbal drugs and their future perspectives. Annals of Phytomedicinevol 5(1), 2016, pp. 1-3.

[23] Uprety Y., Poudel R. C., Asselin H., Boon E. K., Shrestha K. K. Stakeholder perspectives on use, trade, and conservation of medicinal plants in the Rasuwa District of Central Nepal. Journal of Mountain Science, vol. 8(1), 2011, pp. 75-86. 